\title{
E standarización de la técnica de E LISA para el diagnóstico de Toxocariasis humana
}

\author{
YRMA ESPINOZA ${ }^{1,2}$, PEDRO HUAPAYA ${ }^{1}$, ROXANA SUÁREZ † ${ }^{1,2}$, VICTORIA CHÁVEZ4, \\ CARLOS SEVILLA ${ }^{2}$, ELIZABETH DÁVILA ${ }^{1}$, ALINA HUIZA ${ }^{1,2}$, CÉSAR NÁQUIRA ${ }^{1,3}$, PILAR ALVA ${ }^{2}$ \\ ${ }^{1}$ Instituto de Medicina Tropical "Daniel A. Carrión”, UNM SM. "Departamento Académico de \\ M icrobiología M édica - Facultad de Medicina, UNM SM. Instituto Nacional de Salud. \\ "Hospital Nacional "Edgardo Rebagliati Martins" - EsSalud, Servicio de Laboratorio.
}

\begin{abstract}
RESUMEN
OBJETIV 0: Estandarizar la técnica ELISA para el diagnóstico de infección humana por Toxocara canis con antígeno excretado-secretado preparado en nuestro medio. M ATERIAL Y M ÉTODOS: Se colectó huevos de $\mathrm{T}$. canis y se les incubó con formol $(2 \%)$ a $28^{\circ} \mathrm{C}$ hasta obtener larvas de tercer estadio, las que luego de ser liberadas fueron incubadas en RPM I a $37^{\circ} \mathrm{C}$ por 7 días; se reemplazó el medio por otro similar y almacenó a $-20^{\circ} \mathrm{C}$. Se concentró el antígeno y se dosó proteínas. Para la técnica de ELISA se utilizó sueros de pacientes con toxocariasis y de niños recién nacidos, como controles positivos y negativos, respectivamente, diluidos desde $1 / 4$ hasta $1 / 1024$. Se sensibilizó placas de poliestireno con varias concentraciones de antígeno, utilizándose conjugado de peroxidasa e IgG de carnero anti IgG humana y sustrato OPD. Se realizó lectura de absorbancia a $492 \mathrm{~nm}$ con espectrofotómetro ( $M$ ultiskan plus labsystems), siendo el punto de corte el promedio aritmético de la absorbancia de los sueros negativos más 3 desviaciones estándar. RESU LTADOS: L a concentración óptima del antígeno fue $50 \mathrm{ug} / \mathrm{mL}$, la dilución del suero 1/128, la dilución del conjugado 1/1000 con densidad óptica mayor a 0,241. CON CL U SIONES: L a técnica de E L ISA para diagnóstico serológico de infección humana por Toxocara canis podría ser utilizada en estudios epidemiológicos en nuestro país. Queda pendiente la evaluación de su eficacia en futuros estudios.
\end{abstract}

Palabras clave: Toxocara canis; toxocariasis; serología; ELISA.

\section{ELISA TECHNIQUE STANDARDISATION FOR HUMAN TOXOCARIASIS DIAGNOSIS SUM MARY}

OBJ ECTIVE: To standardise ELISA technique for Toxocara canis human infection diagnosis by using excreted-secreted antigen prepared in our country. M ATERIAL AND M ETHODS: T. canis eggs were collected by incubation with formalin $(2 \%)$ at $28^{\circ} \mathrm{C}$ in order to obtain third stage larvae that were freed and incubated in RPM I at $37^{\circ} \mathrm{C}$ for 7 days; the medium was replaced by a similar one and stored at $20^{\circ} \mathrm{C}$. A ntigen was concentrated and protein dosage was made. Sera from patients with toxocariasis and newborns were used as positive and negative controls by ELISA technique, dilutions $1 / 4$ to $1 / 1024$. Polystyrene plates were sensitised with antigen in several concentrations and conjugated peroxidase with horseradish IgG, anti human IgG and substrate OPD were used. Absorbance was read with spectrophotometer (M ultiskan plus labsystems) at $492 \mathrm{~nm}$. Cut off point was determined by negative sera absorbencies arithmetic mean plus 3 standard deviations. RESULTS: A ntigen concentration was $50 \mathrm{ug} / \mathrm{mL}$, sera dilution 1/128, conjugate dilution 1/1000 with optical density above 0,241. CONCLUSIONS: ELISA technique for serologic diagnosis of human infection by Toxocara canis could be used in epidemiological studies in our country. Its efficacy will be determined in future studies. Key words: Toxocara canis; toxocariasis; serology; enzyme-linked inmunosorbent essay.

Correspondencia:

Bióloga Yrma Espinoza Blanco

Instituto de Medicina Tropical "Daniel A. Carrión"

UNMSM - Sección de Parasitología.

Jr. José Santos Chocano 199. Urb. San J oaquín

Bellavista, Callao 02

E-mail: yaeb23@yahoo.es 


\section{INTRODUCCIÓN}

L a toxocariasis es una enfermedad parasitaria accidental del ser humano, causada por un nemátode ascarídeo del género Toxocara, siendo el Toxocara canis, parásito del perro doméstico, el que provoca infección humana con mayor frecuencia ${ }^{(1-3)}$.

El Toxocara es un nemátode cosmopolita, cuya presencia y capacidad parasitaria al ser humano han sido confirmadas en áreas de clima templado y tropical de todos los continentes, considerándose a los habitantes de áreas periurbanas y rurales con deficientes condiciones sanitarias y que no desparasitan a sus mascotas como población de riesgo $(1,2)$.

El parásito desarrolla un ciclo intestinal en los cachorros y un ciclo visceral en los animales adultos, ocurriendo esto último en alguna forma en el ser humano cuando es infectado $(1,2)$.

L a infección se adquiere fácilmente, pues los huevos pueden persistir como infectantes hasta años en suelo húmedo y temperatura templada; también soportan la desecación por su cubierta muy resistente $\left({ }^{2}\right)$. L uego de la ingestión accidental de los huevos, se produce migración de las larvas a diferentes tejidos, causando hemorragia, necrosis, reacción inflamatoria eosinofílica y eventualmente la formación de granulomas. U na gran proporción de infecciones por $T$. canis es asintomática $\left({ }^{2}\right)$. Los órganos más frecuentemente involucrados son hígado, pulmones, cerebro, ojos, corazón y músculos esqueléticos $\left({ }^{1,2}\right)$.

La larva migrans oftálmica es la forma más frecuente $\left({ }^{2,4}\right)$ y severa de la enfermedad, causando endoftalmitis $\left({ }^{5}\right)$; ésta puede ser confundida con un tumor maligno conocido como retinoblastoma $\left({ }^{1,6}\right)$.

Leucocitosis y eosinofilia pueden permanecer como secuelas $(2,7)$. La respuesta inmunológica puede ser intensa, los niveles de anticuerpos permanecen altos durante varios años. $L$ as isohemaglutininas anti $A$ y anti $B$ también permanecen altas $\left({ }^{1}\right.$.
En el Perú, Guerrero, en $1975\left({ }^{8}\right)$, encontró $24 \%$ de 12 parques de Lima contaminados con huevos de Toxocara sp. García, en $1976\left({ }^{9}\right)$, hizo un estudio de preval encia de hel mintos intestinales de perros de un distrito de Lima (San J uan de L urigancho), encontrando $27,7 \%$ en 112 animales estudiados. Cevallos, en $1991\left({ }^{10}\right)$, encontró $31,9 \%$ de perros parasitados con $\mathrm{T}$. canis, y en 8 de 10 parques de diferentes distritos de la ciudad de L ima había presencia de huevos de Toxocara sp. También realizó un estudio seroepidemiológico con el método de ELISA y encontró $7,38 \%$ de positividad a una prueba de inmunoensayo en 1023 sueros $\left({ }^{10}\right)$.

En 1997, M iranda ( ${ }^{11}$ ) señaló en un estudio retrospectivo 21 casos de toxocariasis diagnosticados en Lima.

Estudios en otros países muestran que es más difícil encontrar los huevos en arena $\left({ }^{12}\right)$ que en tierra fértil ( $\left.{ }^{13-16}\right)$, con porcentajes variables entre $15 \%$ a más de $60 \%$. Por lo que se debe considerar la contaminación en parques públicos como un importante factor de riesgo. A demás, el consumo de verduras contaminadas también debe ser tomado en cuenta ${ }^{\left({ }^{17}\right)}$. A simismo, revisando reportes de la frecuencia de infección humana, encontramos que puede variar al rededor de $40 \%\left({ }^{(18-21}\right)$, especialmente en zonas empobrecidas.

Los estudios efectuados en el país indican que la toxocariasis debe ser más frecuente de lo que habitualmente ha sido indicada, pues el diagnóstico directo es difícil de ser realizado en los casos clínicos sospechosos (mediante biopsia); de allí que la demostración indirecta del parasitismo mediante pruebas inmunológicas es importante $(22,23)$.

EI diagnóstico de esta patología actualmente se basa en la sospecha clínica, antecedentes de geofagia y contacto con caninos, un cuadro clínico compatible, leucocitosis y eosinofilia, la cual no siempre existe $\left.{ }^{22,23}\right)$.

Hasta el momento, la prueba de ELISA que utiliza como antígeno el secretado-excretado de 
las larvas del parásito constituye una prueba de alta confiabilidad en la literatura mundial $(16,22,24,25)$.

El propósito del presente trabajo es preparar antígeno excretado-secretado de larvas de T. canis aisladas en nuestra institución y con este antígeno elaborar una prueba de ELISA que permita el diagnóstico apropiado en nuestro medio, tanto en casos clínicos sospechosos como en estudios epidemiológicos.

\section{MATERIAL Y MÉTODOS}

Se preparó el antígeno según el método de Saving $\left.{ }^{26}\right)$, con algunas modificaciones:

- Obtención de ejemplares adultos hembras vivas de Toxocara canis a partir de necropsias de canes menores de seis meses, provenientes del Centro Antirrábico de Chacra Ríos en Lima y otros capturados en comunidades urbano marginales del Callao; también mediante la administración de antiparasitarios a perros mascotas. Con la finalidad de obtener mayor cantidad de vermes, se infectó experimentalmente a perros menores de un mes de edad, los que fueron mantenidos en el Instituto de Medicina Tropical "Daniel A. Carrión" durante más de 2 meses, para luego ser sacrificados y obtener los parásitos del intestino.

- Obtención de larvas de Toxocara canis a partir de las hembras adultas. Se disecó vermes adultos hembras para obtener el útero y colectar huevos, que fueron colocados en recipiente de vidrio con formol al $2 \%$ con tapa de algodón, por 30 a 40 días a $28^{\circ} \mathrm{C}$, agitándolos por lo menos 1 vez al día. Se logró la formación de embriones de los huevos, los que fueron recolectados y lavados por centrifugación 3 a 4 veces, con agua destilada. Se procedió a la liberación de las larvas de tercer estadio; para ello se suspendió los huevos en solución de lejía al 5\%, para reblandecer la membrana; luego se los colocó en recipientes con perlas de vidrio, que fue- ron agitados periódicamente para facilitar que las membranas se rompieran y se produjera la liberación de las larvas, las que fueron recuperadas mediante la técnica de Baerman.

- Las larvas obtenidas previamente fueron colocadas en tubos conteniendo medio líquido para cultivo celular RPM I (Sigma (C), con antibióticos (penicilina 1,000 UI/mL y estreptomicina $250 \mathrm{mg} / \mathrm{mL}$ ), y fueron incubadas a $37^{\circ} \mathrm{C}$ durante 7 días. Se observó al microscopio invertido cada 3 días, para verificar la movilidad de las larvas y descartar una posible contaminación bacteriana y/o fúngica. Después de 7 días, se centrífugó y colectó el sobrenadante, se reemplazó el medio en forma aséptica por otro volumen de composición similar al inicial y se repitió el proceso de incubación de la misma forma. El medio líquido colectado, que contenía el antígeno excretado-secretado o ES, fue almacenado a $-20^{\circ} \mathrm{C}$, hasta obtener un volumen de $200 \mathrm{~mL}$, para luego concentrar el material. Para ello, el antígeno fue colocado en membranas de diálisis que fueron cubiertas con aquacil, durante seis a doce horas, hasta retirar la mayor cantidad de líquido posible. L uego se procedió a dosaje de proteínas del material concentrado mediante el método de Lowry.

- Se estandarizó la prueba de inmunoadsorción asociada a enzimas (ELISA) para detectar anticuerpos de tipo IgG contra T. canis en sueros de pacientes con toxocariasis, procedentes del laboratorio del Hospital Calvo M ackenna de Santiago de Chile, siguiendo la metodología descrita por Glickman y col. ${ }^{(27)}$ con al gunas modificaciones.

Se sensibilizó placas de poliestireno con pocillos de fondo plano con $100 \mathrm{uL}$ de diferentes concentraciones de antígeno ES de T. canis (de 6,25 a $100 \mathrm{ug} / \mathrm{mL}$ ) diluidos en buffer o tampón carbonato-bicarbonato a pH 9,6. Se incubó a $4^{\circ} \mathrm{C}$ durante 18 horas.

Se lavó tres veces con 100 uL por pocillo de una solución de suero fisiológico y Tween 20 
$(0,05 \%)$, durante 5 minutos cada vez. Se bloqueó los sitios de unión inespecíficos con solución de tampón fosfato y albúmina al 1\% (PBSBSA ) (100 uL), incubando a $37^{\circ} \mathrm{C}$ durante 1 hora. Se lavó siguiendo el procedimiento ya descrito. Los sueros de referencia o controles (positivos y negativos) fueron diluidos en PBSBSA en diluciones seriadas de $1: 4$ a $1: 1024$. Se colocó 100 uL de cada dilución en pocillos sucesivos y se incubó a $37^{\circ} \mathrm{C}$ durante 1 hora. Se lavó como ya se ha descrito, se agregó 100 uL de conjugado de IgG de carnero anti IgG humana y peroxidasa de rábano picante a diferentes diluciones ( $1: 1000$ y $1: 2000)$ y se incubó a $37^{\circ} \mathrm{C}$ durante una hora. Se lavó nuevamente, se añadió $100 \mathrm{uL}$ del sustrato orto-fenil-dietnolamina u OPD 0,04\% en tampón citrato $\mathrm{pH} 5,0$ y peróxido de hidrógeno 0,03\% y se incubó a temperatura ambiente durante 30 minutos. Se detuvo la reacción enzimática con 100 uL de ácido sulfúrico $2 \mathrm{~N}$, realizándose la lectura de absorbancia a 492 nm, utilizando un espectrofotómetro o lector de ELISA (Multiskan plus labsystems).

L a titulación fue realizada mediante el método de tablero de damas; para ello se utilizó 8 muestras de suero de niños recién nacidos y de 8 pacientes con diagnóstico serológico de toxocariasis, como controles negativos y positivos, respectivamente. El objetivo era determinar la mejor concentración de antígeno para sensibilizar las placas; además, las diluciones óptimas de suero y conjugado.

El valor de corte fue determinado por el promedio aritmético de la absorbancia de las muestras de sueros negativos más 3 desviaciones estándar.

\section{RESULTADOS}

Con respecto a la obtención del antígeno, luego de 7 días del cultivo de las larvas de T. canis al 5\% en medio RPMI 1640 - Hepes, se obtuvo material producto del metabolismo de Ios parásitos que, al ser concentrado 10 veces con azúcar y/o aquacil, presentó valores de 19,9 $\mathrm{mg} / \mathrm{mL}$ de proteínas.

Con relación al ELISA, después de la titulación, los mejores resultados se obtuvo al emplear antígeno ES a una concentración proteica en $50 \mathrm{~g} / \mathrm{mL}$; la dilución del suero fue 1/128 y la del conjugado $1 / 1000$.

Se determinó el punto de corte en 0,241, luego de promediar las lecturas de densidad óptica de las diluciones de tres sueros negativos menores a la dilución de corte (1/128), siendo el promedio 0,052 y la desviación estándar de $0,063 \mathrm{DO}$. Los valores comprendidos entre $X+2 D E$ y $X+3 D E(0,178$ y 0,241$)$ fueron considerados como indeterminados.

\section{DISCUSIÓN}

El diagnóstico de toxocariasis humana se basa en la detección de anticuerpos específicos antiToxocara en humanos y animales en experimentación $\left({ }^{28,29}\right)$. El método recomendado para el diagnóstico serológico es el método de ELISA, el cual es una prueba de alta sensibilidad y especificidad $(23,24)$. L as placas fueron sensibilizadas con $50 \mathrm{~g} / \mathrm{mL}$, teniendo resultados comparables con los del L aboratorio de Inmunología del Hospital Calvo Mackenna de Santiago de Chile, que es considerado como centro de referencia.

La reactividad al antígeno de Toxocara en sueros de pacientes con otras infecciones parasitarias ha sido reportada principalmente a la causada por A. lumbricoides, nemátode que comparte antígenos comunes con Toxocara $(20,21,24,27)$. $\mathrm{N}$ o hemos evaluado sueros de pacientes que sólo tuvieran infección por A. lumbricoides. Para disminuir la reactividad cruzada, se recomienda la adsorción del suero a evaluar con antígenos de $A$. suun $\left({ }^{29}\right)$, hecho que no se realizó en el presente trabajo y que se efectuará posteriormente.

E s importante compl etar este estudio evaluando un mayor número de muestras de suero posi- 
tivo y negativo, para poder tener una mejor idea de la eficacia de ELISA como método de diagnóstico y/ tamizaje que, en caso de ser adecuada, permitiría su uso en estudios epidemiológicos.

En conclusión, el cultivo de 7 días con RPM I - Hepes de larvas al $5 \%$ es un método de cultivo que permite obtener material rico en proteínas y antígeno, posible de ser empleado para realizar pruebas serológicas. En nuestro medio, el valor de corte a emplearse debe de ser la densidad óptica mayor a 0,142 para la dilución 1/128, toda vez que diluciones menores no tienen carácter discriminante entre los sueros positivos y negativos. La mejor concentración de antígeno utilizado para la sensibilización de las placas es de $50 \mathrm{~g} / \mathrm{mL}$. Debido a que no tenemos certeza de las reacciones cruzadas y por el alto grado de parasitismo por helmintos en nuestro país, sería conveniente realizar la adsorción de los sueros con antígeno de Ascaris suun antes de aplicar E LISA. Queda pendiente la evaluación de la eficacia de la técnica en futuros estudios, antes de recomendar su uso como método de diagnóstico y/o tamizaje en nuestro país.

\section{A GR A DE CIM IE NTO}

Este trabajo fue financiado por el Consejo Superior de Investigación de la UNM SM. Código: 90101251.

\section{BIBLIOGRAFÍA}

1. Taranto $\mathbf{N}$, Passamonte $L$, Marincon $R$, de $M$ arzi $M$, Cajal S, Malchiodi E. Parasitosis zoonóticas transmitidas por perros en el Chalco salteño. M edicina 2000; 60(2): 217-20.

2. Flores A. Toxocariosis: zoonosis por nematodos. Rev Nuestros Perros, M adrid, España, N 5, abril 1992.

3. Schenone H. Parasitosis humanas que pueden ser causadas 0 transmitidas por mascotas domésticas en Chile. Bol Chil Parasitol 1987; 42: 16-23.

4. Nichols R. The etiology of visceral larva migrans. J Parasitol 1956; 42: 349-62.

5. Wilder H. Nematode endophthalmitis. A mer A cad O pthal 1950; 55: 99-109.
6. L ópez-V élez A, Suárez M, Jimeno L, G arcía-C amacho A, F enoy S, G uillen J , C astellote L. ¿Toxocariosis ocular o retinoblastoma?. Enferm Infecc M icrobiol Clin 1995; 13: 4 .

7. B eaver P, Snyder H, Carrera G, Dent J, Lafferty J. Chronic eosinophilia due to visceral larva migrans. Pediatrics 1952; 9: 7-19.

8. Guerrero M. Estudio de la contaminación de parques públicos de Lima M etropolitana con huevos de Toxocara sp. Tesis de Bachiller en M edicina Veterinaria, U niversidad de San Marcos, Lima - 1975.

9. García E. Prevalencia de helmintos gastrointestinales en C anis familiaris en el distrito de L urigancho, Chosica, Departamento de L ima. T esis de Bachiller en M edicina $V$ eterinaria U niversidad N acional M ayor de San M arcos. 1976.

10. Zevallos L. Estudio epidemiológico da T oxocariase na area U rbana de L ima, Perú. Tesis para optar el titulo de M aster en Parasitología. U niversidad de Sao Paulo.1991.

11. M iranda J, Sousa A, Alzamora B, M aquiña C, Tobaru L, Y arleque C, Terashima A y G ottuzo E. Primer reporte en el Perú de toxocariasis ocular: análisis de 21 casos. Bol Soc Per M ed Interna 1999; 12: 20-8.

12. Nunes C, Pena F, Negrelli G, A njo C, Nakano M, Stobbe N. Ocorrêcencia de larva migrans na aerina de areas de lazer das escolas municipais de encino infantil, A raçatuba, SP, Brasil. Rev Saúde Pública 2000; 35(6).

13. Ribeiro F, Crocci A, Carneiro R, Silva J, Miyoshi M, Pessoa F, da Silva M y L ima M. Contaminaçao de praças públicas de Campo Grande, M ato Grosso do Sul, Brasil, por ovos de Toxocara e Ancylostoma em fezes de cães". Rev Soc Bras M ed Trop 1999; 32(5), U beraba.

14. Vásquez $\mathbf{0}$, Ruiz A, Martínez I, Merlín P, Tay J, Pérez A. Contaminación de suelos por huevos de Toxocara sp. en parques públicos y jardines de casas habitación de la ciudad de M éxico. Bol Chil Parasitol 1996; 51: 54-8.

15. Laird R, Carballo D, Reyes E, García R, Prieto V. Toxocara sp. en parques y zonas públicas de Ciudad de la Habana, 1995. Rev Cubana Hig Epidemiol 2000; 38(2): 112-6.

16. Jiménez J, Valladares B, Fernández J, Armas F, del Castillo A. A serologic study of human toxocariasis in the Canary Islands (Spain): Environmental influences. Am J Trop Med Hyg 1997; 56(1): 113-5.

17. Vásquez $\mathbf{0}$, M artínez I, Tay J, R uiz A, Pérez A. V erduras de consumo humano como probable fuente de infección de Toxocara sp. para el hombre. Bol Chil Parasitol 1996; 51: 47-50.

18. Agudelo C, Villareal E, Cáceres E, López C, Eljach J, Ramírez N, Hernández C, Corredor A. Human and dogs Toxocara canis infection in a poor neighborhood in Bogota. M em Inst O swaldo Cruz, Rio de J aneiro 1990; 85(1): 75-8.

19. Alonso J, Bojanich M, Chamorro M, Gorodner J. Toxocara seroprevalence in children from a subtropical city in A rgentina. Rev Inst M ed Trop S Paulo 2000; 42(4), Sao Paulo. 
20. Moreira S, Leao M, Mendonca H, Pereira F. Prevalence of anti-Toxocara antibodies in a random sample of inpatients at a Children's hospital in V itoria, Espírito Santo, Brazil. Rev Inst M ed Trop S Paulo 1998; 40 (4): 259-61.

21. Triviño X, Bedregal P, Torres $\mathbf{M}, \mathbf{C}$ anales $\mathbf{M}$, Alvarado C, Hernández R. Toxocariosis en Chile: serie clínica en un centro de pediatría ambulatoria. Parasitología al día 1999; 23(3-4).

22. $M$ invielle $M$, Niedfeld $M$, Ciarmela $M$, Basualdo J . Toxocariosis causada por Toxocara canis aspectos epidemiológicos. Enferm Infecc M icrobiol Clin 1999; 17: 300-6.

23. Noemí J, Viovy A, Cerva J, Gottlieb B, Roncone E, Quera R, Soto S, Herrera A, Fierro O, Fuentealba M, Contreras A, Berrios R. Perfil clínico de la Toxocariasis en pediatría. Parasitología al día 1992; 16: 91-7.

24. de Savigny D, Voller A, Woodruff W. Toxocariasis: serological diagnosis by enzyme immunoassay. J Clin Pathol 1979; 32: 284-8.
25. Nunes C, Tundisi R, Heinemainn M, Richtzenhan L. Toxocariasis: serological diagnosis by indirect antibody competition ELISA. Rev Inst M ed Trop S Paulo 1999; 41(2): 95- 100.

26. de Savingny D. In vitro maintenance of Toxocara canis larvae and a simple method for the production of Toxocara ES antigens for use in serodiagnostic tests for visceral larva migrans. J Parasit 1975; 61: 781-2.

27. Glickman L, Schantz P, Dombroske R, Cypess R. Evaluation of serodiagnostic test for visceral larva migrans. A m J Trop M ed Hyg 1978; 27(3): 492-8.

28. Chieffi P, Peres B, de M ello E, Kabanura H, Brandao $\mathbf{M}$. Persistence of specific antibody response in different experimental infections of mice with Toxocara canis larvae. Rev Inst Med Trop S Paulo 1995; 37(3).

29. Cevallos $\mathbf{S}$. Toxocara canis resposta de anticorpos Ig $G$ na infeccao murina experimental e na co-infeccao com outros parasitos. Sao Paulo, 1998. Rev Inst Med Trop S Paulo 1998; 40(6): 350. 